\title{
Comparative study of self-expanding metal stent and intraluminal radioactive stent for inoperable esophageal squamous cell carcinoma
}

\author{
Dong $\operatorname{Tian}^{\dagger}$, Hongying $\mathrm{Wen}^{\dagger}$ and Maoyong $\mathrm{Fu}^{*}$
}

\begin{abstract}
Background: We compared the effectiveness of self-expanding metal stent alone vs. radioactive stent embedded with ${ }^{125}$ seeds implantation insertion in patients of inoperable esophageal squamous cell cancer combined with malignant esophageal stenosis.

Methods: We studied two groups of patients with stenosis attribute to inoperable esophageal squamous cell carcinoma. Group A had placed self-expanding metal stent alone insertion; group B encountered radioactive stent embedded with ${ }^{125}$ I seeds. Patients were followed up by monthly home visits or telephone interview. Survival time was analyzed with Kaplan-Meier analysis. Log rank test was used to analyze factors of survival time for all significant differences.
\end{abstract}

Results: There was no significant difference between the two groups of all baseline characteristics. There was no statistical difference in complications including massive hematemesis, pain more than 1 month, stent migration, and restenosis. Survival time and causes of death such as tumor metastasis, massive hemorrhage, non-tumor-related factors, and restenosis were comparable between the two groups $(P>0.05)$. The medical costs were significantly less in group A than those in group $B(P<0.01)$.

Conclusions: Radioactive stent embedded with ${ }^{125}$ seeds was not significant in improving survival rate, but showed to increase hospitalization costs compared to self-expandable metal stent alone in treating inoperable esophageal squamous cell carcinoma stricture.

Keywords: Self-expanding metal stent, Intraluminal radioactive stent, Esophageal squamous cell carcinoma, Malignant esophageal stricture, Clinical curative effect

\section{Background}

Esophageal cancer has a high morbidity and mortality rate than other malignant tumors. Dysphagia is the most common symptom in esophageal cancer, has serious impact on nutrient intake, and threatens the lives of patients [1, 2]. More than half of the patients need palliative treatment to relieve progressive esophageal stricture [3]. To remove the stenosis of esophageal cancer and improve the quality of life of patients with

\footnotetext{
* Correspondence: fumaoyongmd@126.com

${ }^{\dagger}$ Equal contributors

Cardiothoracic Surgery Department, Affiliated Hospital of North Sichuan Medical College, Nanchong 637000, China
}

esophageal cancer, stent placement is the best choice to improve the symptom caused by dysphagia [4-7]. In 1983, Frimberger [8] treated a patient diagnosed with esophageal stricture placed with a metal stent. Metal stents became more and more popular for patients who encountered dysphagia $[9,10]$. Recently, an esophageal stent embedded with iodine-125 $\left({ }^{125} \mathrm{I}\right)$ seeds (also called intraluminal radiotherapy) has been developed $[11,12]$. These two kinds of stents are more and more useful for inoperable esophageal cancer [13-17]. Both stents have been demonstrated as effective with few complications, although their relative effectiveness is unknown. However, there was great controversy to self-expanding 
metal stent and intraluminal radioactive stent in clinical curative effects, survival time, complications, hospital stay, and cost $[11,12,18-24]$. In our study, the selfexpanding metal stent was compared with the radioactive stent embedded with ${ }^{125}$ I seeds in treating inoperable esophageal squamous cell carcinoma.

\section{Methods}

\section{Patients}

The study was approved by the institutional ethics committee of the Affiliated Hospital of North Sichuan Medical College. Informed consent was obtained from all enrolled patients. A total 131 patients with inoperable esophageal squamous carcinoma were selected for prospective nonrandomized study. Group assignment was based on physician's professional assessment as well as the patient's own preference. Self-expandable metallic stent was performed in 91 patients (group A) and intraluminal radioactive stent was performed in 40 patients (group B) at the Affiliated Hospital of North Sichuan Medical College between September 2013 and June 2015.

The specific inclusion criteria were as follows:

1. The pathological diagnosis was esophageal squamous cell carcinomas.

2. Stenosis by tumor invasion.

3. Physical fitness score (Karnofsky score) $\geq 50$

4. Expected to survive no less than 1 month.

5. No other organs encountered serious dysfunction.

6. No chemotherapy or radiotherapy was performed before and after stent implantation.

7. No chance to R0 resection for surgery (e.g., local lymphadenomegaly; tumor had invaded adjacent $\operatorname{organ}(\mathrm{s}))$.

The exclusion criteria were as follows:

1. Esophageal fistula.

2. The neck segment esophageal cancer.

3. Inability to obey follow-up.

4. Whatever the cause, stent placement was given up halfway.

5. Esophageal adenocarcinoma and esophagogastric junction carcinoma.

6. Patients rejected stent placement by personal reasons.

\section{Dysphagia score}

Ogilvie's dysphagia score classification is as follows: grade 0 , to be able to eat the ordinary diet; grade 1 , to be able to eat the solid food; grade 2 , to be able to eat the semisolids; grade 3, to be able to take liquids food; and grade 4 , to be able to eat nothing [25].

\section{Stent and ${ }^{125}$ I seeds}

The system of self-expanding metal stent contains two elements: esophageal stent formed by nitinol and covered by silicone membrane. Besides the two parts, intraluminal radioactive stent is also composed of another nitinol sheath outside of the stent, which can contain ${ }^{125}$ I seeds (Nanjing Micro-tech Co., Ltd, Nanjing, China).

The radioactive seeds of ${ }^{125} \mathrm{I}$ (Bejing ZHIBO Biomedical Technology Co., Ltd, Beijing, China) are wrapped up in titanium alloy. Parameters of seeds are as follows: $4.5 \mathrm{~mm}, 0.8 \mathrm{~mm}, 60.1$ days, $27-35 \mathrm{keV}, 1.7 \mathrm{~cm}$ in length, diameter, half-life, mean photon energy, and tissue penetration. The original dosage rate was $7 \mathrm{cGy} / \mathrm{h}$. Activity of each seed for clinical use is $0.80-0.90 \mathrm{mCi}$.

\section{Stent placement}

Before stent placement, esophagoscope, computerized tomography (CT), and barium meal was used to confirm the tumor site, stricture degree, and length of tumor. The parameters of the stent were assessed according to the measured length of the tumor. The stent should be chosen more than $2 \mathrm{~cm}$ at both ends of the tumor. The stent implantation process of the two types of stents was in the same method. The esophagus was able to selectively enlarge according to the degree of the esophageal stenosis. Dilation was necessary when it was required to place the stent to a maximum of $11 \mathrm{~mm}$ by a SavaryMiller esophageal dilator (Changzhou Jiuhong Medical Instrument Co., Ltd.).

\section{Observation}

Baseline characteristics were gender, age, tumor location, complications before stent placement, local lymph node enlargement (short diameter of lymph node $\geq 8 \mathrm{~mm}$ in the cervical region, mediastinum, abdomen), tumor stage (seventh edition of the AJCC and UICC), time of stent placement, length of tumor, length of stent, and esophagus dilation. Clinical curative effects were based on dysphagia score and tumor regression (smaller on the maximum section area of CT). The complications were sudden massive hemorrhage within the first month, pain more than 1 month, stent migration, and restenosis. Hospital stays and medical costs, survival time, and death causes were also identified.

\section{Followed up}

Patients were followed up by monthly telephone interview or home visits from a specialized doctor. All the patients were followed up until July 2015 or death.

\section{Statistical analysis}

Statistical software package SPSS 22.0 (SPSS, Inc., Chicago, IL) was used for all the data analyses. Mean \pm standard deviation and range expressed the numeric data. 
Student's $t$ test, $\chi^{2}$ test, Kaplan-Meier method, and logrank test were applied in our study. $P<0.05$ was considered to indicate a statistically significant difference.

\section{Results}

\section{Patient characteristics}

The median follow-up period in both groups A and B were 4 months. Stent placement was successful in both groups. The baseline characteristics of both groups were detailed in Table 1 . There were no statistically significant differences in the gender, age, tumor location, complications before stent placement, local lymph node enlargement, tumor stage, time of stent placement, length of tumor, length of stent, and esophagus dilation between the two groups $(P>0.05)$.

\section{Clinical curative effects}

The dysphagia score was improved in the two groups after stent placement. Three cases $(7.5 \%)$ of tumor growth were inhibited in group B after 3 months, group A did not, as shown in Table 2.

\section{Complications}

There were no statistically significant differences in the sudden massive hemorrhage, pain more than 1 month, stent migration, or restenosis in both groups $(P>0.05)$, as shown in Table 3.

(1) Massive hemorrhage: No patient encountered sudden massive hemorrhage during stent placement, but this complication developed in six $(6.6 \%)$ and one (2.5\%) patients in group A and group B, respectively, post placement; all of which were fatal.

(2) Pain: Most of the patients encountered retrosternal pain after the stent placement and part of the patients felt severe chest pain, which was relieved using narcotic analgesics. Sixteen patients in group A and 12 patients in group B felt severe pain more than 1 month, and no statistically significant differences were identified between the two groups $(P>0.05)$.

(3) Stent migration: Five patients in group A and two patients in group B experienced stent migration 2 months after stent placement, confirmed by electronic endoscopy or barium meal. Re-intervention by

Table 1 The baseline characteristics of studied groups

\begin{tabular}{|c|c|c|c|}
\hline Characteristics & Group A $(n=91)$ & Group B $(n=40)$ & P \\
\hline Gender, $n(\%)$ & & & $0.869^{c}$ \\
\hline Male & $67(73.6 \%)$ & $30(75 \%)$ & \\
\hline Female & $24(26.4 \%)$ & $10(25 \%)$ & \\
\hline Age (years, mean \pm SD) (range) & $66.3 \pm 9.4(43-90)$ & $66.9 \pm 8.6(47-84)$ & $0.700^{d}$ \\
\hline Location of cancer, $n(\%)$ & & & $0.195^{c}$ \\
\hline Proximal third & $15(16.5 \%)$ & $3(7.5 \%)$ & \\
\hline Middle third & $66(72.5 \%)$ & $29(72.5 \%)$ & \\
\hline Distal third & $10(11.0 \%)$ & $8(20.0 \%)$ & \\
\hline Complications before stent placement, $n(\%)$ & & & $0.601^{c}$ \\
\hline Yes & $41(46.1 \%)$ & $20(50 \%)$ & \\
\hline No & $50(55.9 \%)$ & $20(50 \%)$ & \\
\hline Local lymph node enlargement, $n(\%)^{a}$ & & & $0.686^{c}$ \\
\hline Yes & $69(75.8 \%)$ & $29(72.5 \%)$ & \\
\hline No & $22(24.2 \%)$ & $11(27.5 \%)$ & \\
\hline Tumor stage, $n(\%)^{b}$ & & & $0.437^{c}$ \\
\hline III & $61(67.0 \%)$ & $24(60.0 \%)$ & \\
\hline IV & $30(33.0 \%)$ & $16(40.0 \%)$ & \\
\hline Time of stent placement (min, mean \pm SD) (range) & $22.6 \pm 4.9(15-35)$ & $20.2 \pm 4.7(14-32)$ & $0.792^{d}$ \\
\hline Length of tumor (cm, mean $\pm \mathrm{SD}$ ) (range) & $5.3 \pm 1.3(3-10)$ & $5.5 \pm 1.5(2.5-8)$ & $0.139^{d}$ \\
\hline Length of stent (cm, mean $\pm S D$ ) (range) & $9.3 \pm 2.0(6-16)$ & $10.5 \pm 1.6(6-14)$ & $0.274^{d}$ \\
\hline Esophagus dilation, $n(\%)$ & & & $0.775^{c}$ \\
\hline Yes & $57(62.6 \%)$ & $24(60 \%)$ & \\
\hline No & 34 (37.4 \%) & 16 (40 \%) & \\
\hline
\end{tabular}

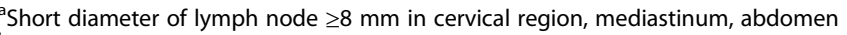

${ }^{\mathrm{b}} 7$ th edition of the AJCC\&UICC

${ }^{c} X^{2}$ exact test was used

${ }^{d}$ Student's $t$ test was used 
Table 2 Clinical curative effects

\begin{tabular}{lll}
\hline & Group A $(n=85)$ & Group B $(n=32)$ \\
\hline $\begin{array}{l}\text { Ogilvie's dysphagia score (prior stent placement), } n(\%) \\
3\end{array}$ & $66(72.5 \%)$ & $29(72.5 \%)$ \\
4 & $25(27.5 \%)$ & $11(27.5 \%)$ \\
Ogilvie's dysphagia score (post stent placement) ${ }^{\mathrm{a}}, n(\%)$ & & \\
0 & $73(80.2 \%)$ & $28(70.0 \%)$ \\
1 & $18(19.8 \%)$ & $12(30.0 \%)$ \\
Tumor regression, $n(\%)^{\mathrm{b}}$ & & $3.200^{c}$ \\
Yes & $0(0 \%)$ & $3(7.5 \%)$ \\
No & $91(100 \%)$ & $37(92.5 \%)$ \\
\hline
\end{tabular}

a days after stent implantation

${ }^{\mathrm{b}}$ Smaller on the maximum section area of $\mathrm{CT}$

${ }^{c} X^{2}$ exact test was used

${ }^{d} P<0.05$ was considered to indicate a statistically significant difference

gastroscope assistance was successful on these seven patients.

(4) Restenosis: Four patients in group A and two patients in group B experienced restenosis 3 months after stent placement, confirmed by barium meal and/or gastroendoscopy. No patient chose to undergo further treatment.

(5) Others: There were no radioactive pneumonia, bone marrow suppression, gastrointestinal reaction, and other complications related to radiotherapy in group $\mathrm{B}$.

\section{Hospital stays and medical costs}

The hospital stays were shorter in group A than those in group $B$, but this did not reach statistical significance difference: 8.9 vs. 10.1 days, respectively $(P>0.05)$. The medical costs were significantly less in group $A$ than those in group B: $¥ 7000$ vs. $¥ 26,000$, respectively $(P<0.01)$.

Table 3 Complications post to stent placement

\begin{tabular}{llll}
\hline & Group A, n (\%) & Group B, n (\%) & $P$ \\
\hline $\begin{array}{llll}\text { Massive hemorrhage } \\
\text { Yes }\end{array}$ & $6(6.6 \%)$ & $1(2.5 \%)$ & $0.337^{\mathrm{b}}$ \\
No & $85(93.4 \%)$ & $39(97.5 \%)$ & \\
Pain more than 1 month & & & $0.110^{\mathrm{b}}$ \\
$\quad$ Yes & $16(17.6 \%)$ & $12(30.0 \%)$ & \\
No & $75(82.4 \%)$ & $28(70.0 \%)$ & \\
Stent migration & & & $0.908^{\mathrm{b}}$ \\
Yes & $5(5.5 \%)$ & $2(5.0 \%)$ & \\
No & $86(94.5 \%)$ & $38(95.0 \%)$ & \\
Restenosis & & & $0.879^{\mathrm{b}}$ \\
Yes & $4(4.4 \%)$ & $2(5.0 \%)$ & \\
No & $87(95.6 \%)$ & $38(95.0 \%)$ & \\
\hline
\end{tabular}

${ }^{a}$ In the first month after stent placement

${ }^{\mathrm{b}} \mathrm{X}^{2}$ exact test was used

\section{Survival time and death causes}

The mean survival time in group A and group B was $4.2 \pm 2.8(0-15)$ months and 4.4 $\pm 2.4(0-9)$ months, respectively. The Kaplan-Meier curves were shown in Fig. 1. There was no significant differences in the survival time $(P=0.752>0.05)$. The main death causes were tumor metastasis $(40.7 \%$ vs. $40.0 \%)$ and massive hemorrhage (30.8 \% vs. $27.5 \%$ ), as shown in Table 4 . Among these death causes, 96 patients (group $A=68$, group $B=28$ ) died of esophageal cancer. The mean disease specific survival time in group A and group B was $3.4 \pm 0.3$ and $3.7 \pm 0.4$ months, respectively. The KaplanMeier curves were shown in Fig. 2. There was no significant difference in survival $(P=0.421>0.05)$.

\section{Discussion}

Advanced esophageal squamous cell carcinoma may cause dysphagia. Dysphagia is the main symptom of patients with inoperable esophageal squamous cell carcinoma [1]. Most of them need the palliative care to relieve this symptom [3].

Although esophageal bypass surgery has been performed to enable oral ingestion, the outcome of this palliative surgery is not always favorable because it is extremely invasive for the patients in an unstable condition as a result of advanced cancer [26-28]. In contrast, the insertion of an esophageal stent has many advantages for such patients because it is much less invasive and the procedure is simpler and safer than bypass surgery. Recently, stenting has been considered to be the best way of treatment for malignant stenosis.

These work compared the self-expanding metal stent alone and intraluminal radioactive stent loaded with ${ }^{125} \mathrm{I}$ seeds for palliation of dysphagia due to inoperable squamous carcinoma of the esophagus.

Although various studies have described, intraluminal radioactive stent got a better long-term clinical effect of 


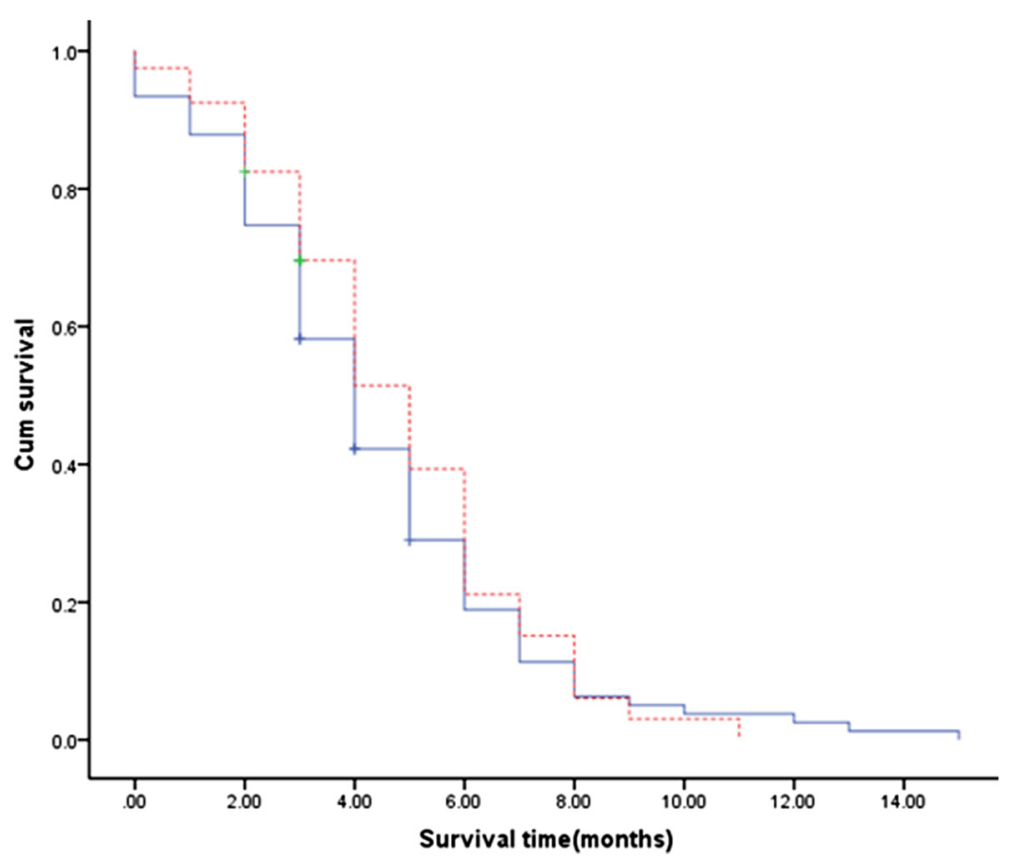

Fig. 1 Intraluminal radioactive stent self-expanding metal stent. Kaplan-Meier curves of overall survival. Comparison of overall survival between group A (self-expanding metal stent) and group B (intraluminal radioactive stent). The mean overall survival period was similar in group A compared with that in group B: $4.2 \pm 2.8(0-15)$ months vs. $4.4 \pm 2.4(0-9)$ months, respectively. There was no significant difference in survival time $(P>0.05)$

dysphagia and went with fewer complications. Moreover, the median survival time was also longer in intraluminal radioactive stent than self-expanding metal stent alone. Our study showed no significance evidence of this fact in inoperable esophageal squamous cell carcinoma.

All patients in our study were inoperable of advanced esophageal cancer who chose self-expanding metal stent (group A) and the radioactive stent embedded with ${ }^{125} \mathrm{I}$ seeds (group B) voluntarily. Both stent placements were clinically successful. There was no death during stent implantation.

The score of dysphagia was improved greatly in all patients after stenting, and there was no statistically significant difference between groups A and group B. Three months after stent placement, 4 patients in group A and 2 patients in group B experienced restenosis. The causes of restenosis after placement may be due to the granulation hyperplasia tissue and/or tumor tissue growing into the ends of the stent [24]. No patient in our study encountered restenosis because of the regrowth of the tumor tissue.

Three months later, three cases $(7.5 \%)$ with tumor growth was inhibited in group B, group A did not. This demonstrated that the intraluminal radioactive stent had the effect of inhibiting tumor growth and the hyperplasia of the granulation tissue.

The main complications following the stent placement include massive hematemesis, pain more than 1 month, stent migration, and restenosis [13, 29-33]. There was no statistical significance difference between group A and group B in these outcomes.

Hemorrhaging after stent placement has been reported about 3-8 \% and most of the time was self-limited [1]. This incidence has also been reported as much as $30 \%$ in part of the study [11]. In our study, six patients in group A and one in group B encountered massive hemorrhaging in 1 month after stent placement, but no patients succumbed during the process of stent placement.

Table 4 Death causes

\begin{tabular}{lll}
\hline Death causes & Group A $(n=86)$ & Group B $(n=35)$ \\
\hline Tumor metastasis, $n(\%)$ & $37(40.7 \%)$ & $16(40.0 \%)$ \\
Massive hemorrhage, $n(\%)$ & $28(30.8 \%)$ & $11(27.5 \%)$ \\
Non-tumor-related factors, $n(\%)$ & $18(19.8 \%)$ & $7(17.5 \%)$ \\
Restenosis, $n(\%)$ & $3(1.1 \%)$ & $1(2.5 \%)$ \\
\hline
\end{tabular}

$x^{2}$ exact test was used 


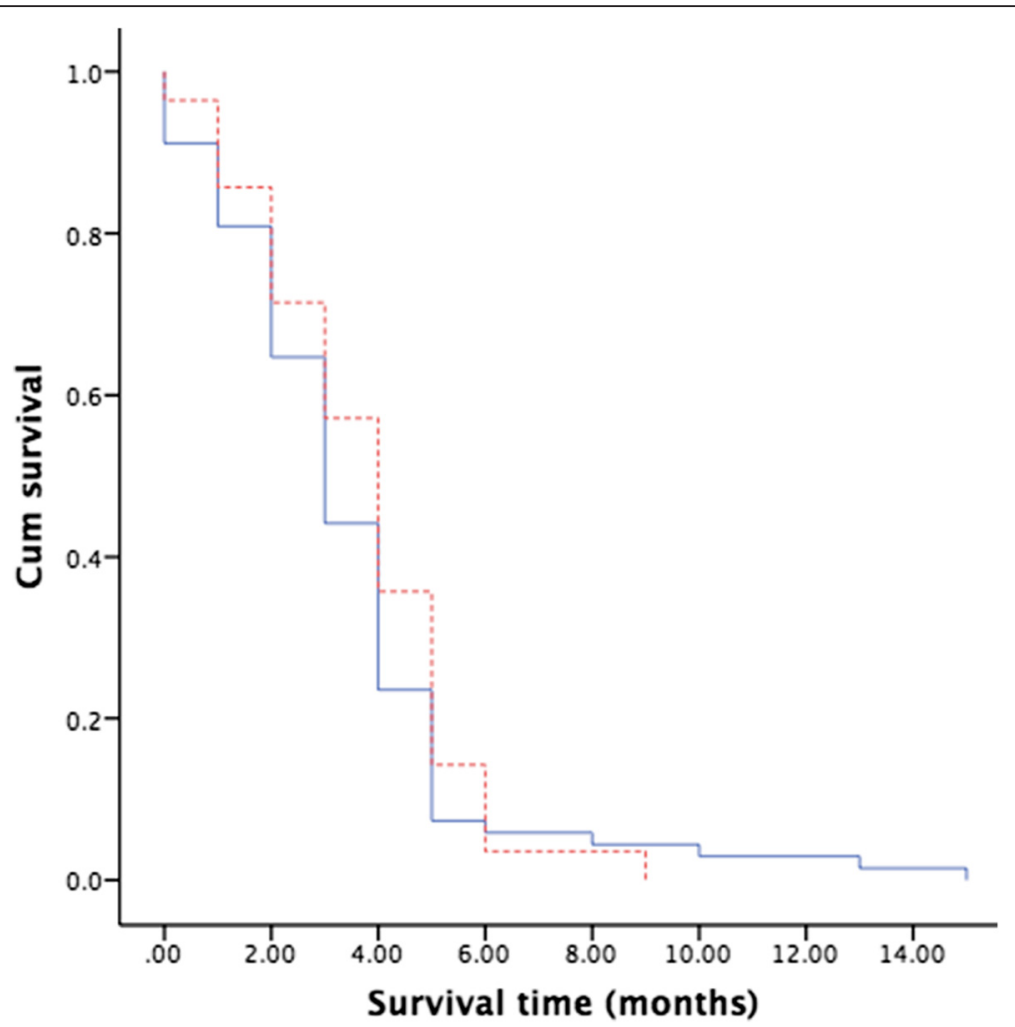

Fig. 2 Intraluminal radioactive stent, self-expanding metal stent. Kaplan-Meier curves of disease-specific survival. Comparison of disease-specific survival between group A (self-expanding metal stent) and group B (intraluminal radioactive stent). The mean disease-specific survival period was similar in group A compared with that in group B: $3.4 \pm 0.3$ months vs. $3.7 \pm 0.4$ months, respectively. There was no significant difference in survival $(P>0.05)$

In our study, most of the patients encountered retrosternal pain after the stent placement and part of the patients felt severe chest pain, which was relieved using narcotic analgesics. Sixteen patients in group A and 12 patients in group B felt severe pain more than 1 month, and no statistically significant difference was identified between the two groups. That was lower than has been observed in previous research (53.8\%) [34]. No patient stopped stent treatment because of severe pain.

Five cases in group A and two cases in group B experienced stent migration 2 months after stent placement, confirmed by electronic endoscopy or barium meal. Reintervention by gastroscope assistance was successful on these patients. That should be due to the nature of the nickel-titanium shape memory alloy stents. Cold temperature will make the stent soften. When the temperature reaches more than $37{ }^{\circ} \mathrm{C}$ for 1 week, the stent will form a shape that does not change in response to cold temperatures. In order to prevent the stent from deformation or shifting, cold foods could be taken no less than 1 week after stenting [24].

The hospital stays were shorter in group A than those in group B, but there was no statistically significant differences: 8.9 vs. 10.1 days, respectively. Few studies reported hospital stays, but found longer compared to those of our study. The medical costs were significantly less in group A than those in group B: $¥ 7000$ vs. $¥ 26,000$, respectively. Some of other previous studies found that there was no significant differences between the total medical costs of metal stent placement vs. radiotherapy in the palliative treatment of esophageal squamous cell cancer $[18,19]$.

The mean survival time in group A and group B was $4.2 \pm 2.8(0-15)$ months and $4.4 \pm 2.4(0-9)$ months, respectively. There was no statistical significance difference in survival time $(P>0.05)$. Besides, the diseasespecific survival better reflects the impact of stent placement on the survival of patients. In this study, the mean disease-specific survival time in group A and group B was $3.4 \pm 0.3$ and $3.7 \pm 0.4$ months, respectively. There was also no statistical significance difference in survival $(P>0.05)$. The main death causes were tumor metastasis $(40.7 \%$ vs. $40.0 \%)$ and massive hemorrhage $(30.8 \%$ vs. $27.5 \%)$. Although various studies [11, 12, 18, 35] have described a longer survival time of intraluminal radioactive stent than that of self-expanding metal stent, our results showed no evidence of significance supporting this fact in inoperable esophageal squamous cell cancer. 
The reason of this difference may be attributed to different case compositions. All the patients in our research were only at advanced stage (III, IV stage) and esophageal squamous cell carcinoma; however, other studies included early/advanced stage (II, III, IV stage) patients and esophageal adenocarcinoma/adenocarcinoma of the esophagogastric junction.

Theoretically, radioactive stent embedded with ${ }^{125} \mathrm{I}$ seeds implantation may be better than self-expanding metal stent alone insertion because of the different types of stent to the tumor. Intraluminal radioactive stent provides closer, longer continuous radiotherapy with tumors. Nevertheless, the dose of radiation with radioactive stent in the esophageal lumen was too difficult to precisely measure and plan. Therefore, an accurate dose of ${ }^{125} \mathrm{I}$ seeds was important. Unfortunately, there was no treatment planning system (TPS) for luminal organs. The TPS that we used mainly depended on the design of solid tumors.

In the present study, the main death causes were tumor metastasis and massive hemorrhage. Although three cases of tumor growth were inhibited, there was no significant effect of radioactive stent to inhibit tumor metastasis and massive hemorrhage.

Some inevitable limitations also could be found in our study. Firstly, the sample size of the present study was considered small, although it reached the statistical significance which could be due to the time limitation and inclusion criteria. Our further studies with bigger sample sizes may make more accurate results. Secondly, the quality of life for these patients, an important measure to assess for the palliative treatment of cancer, including inoperable esophageal squamous cell cancer, was not measured in our study.

\section{Conclusions}

Intraluminal radioactive stent embedded with ${ }^{125}$ I seeds implantation was not significant when it came to the outcome of survival benefit, but increased the hospitalization expense than self-expandable metal stent alone in treating inoperable esophageal squamous cell carcinoma stricture.

\section{Consent for publication}

Informed consent for publishing the individual patient data was obtained from all the participants.

\section{Competing interests}

The authors declare that they have no competing interests.

\section{Authors' contributions}

DT and HW were involved in the manuscript preparation, reference literature review, and program design. MF participated in the clinical data collection and manuscript amendment. All authors read and approved the final manuscript.

\section{Acknowledgements}

This study did not receive any specific funding. We appreciate the contribution and the valuable assistance of Dr. Shunran Ma and Dr. Shaofu Yang of the Cardiothoracic Surgery Department, Affiliated Hospital of North Sichuan Medical College.

\section{Funding}

There are currently no funding sources in the list.

Received: 24 November 2015 Accepted: 11 January 2016

Published online: 22 January 2016

\section{References}

1. Katsanos K, Sabharwal T, Adam A. Stenting of the upper gastrointestinal tract: current status. Cardiovasc Intervent Radiol. 2010;33(4):690-705. doi:10.1007/s00270-010-9862-6. Epub 2010 Jun 3.

2. Park JG, Jung GS, Oh KS, Park SJ. Double-layered PTFE-covered nitinol stents: experience in 32 patients with malignant esophageal strictures. Cardiovasc Intervent Radiol. 2010;33(4):772-9. doi:10.1007/s00270-009-9718-0. Epub 2009 Sep 29.

3. Parkin DM, Bray FI, Devesa SS. Cancer burden in the year 2000. The global picture. Eur J Cancer. 2001;37 Suppl 8:S4-66.

4. Knyrim K, Wagner $\mathrm{HJ}$, Bethge $\mathrm{N}$, Keymling M, Vakil N. A controlled trial of an expansile metal stent for palliation of esophageal obstruction due to inoperable cancer. N Engl J Med. 1993:329(18):1302-7.

5. Song HY, Do YS, Han YM, Sung KB, Choi EK, Sohn KH, et al. Covered, expandable esophageal metallic stent tubes: experiences in 119 patients. Radiology. 1994;193(3):689-95.

6. Christie NA, Buenaventura PO, Fernando HC, Nguyen NT, Weigel TL, Ferson PF, et al. Results of expandable metal stents for malignant esophageal obstruction in 100 patients: short-term and long-term follow-up. Ann Thorac Surg. 2001;71(6):1797-801. discussion 1801-2.

7. Sabharwal T, Hamady MS, Chui S, Atkinson S, Mason R, Adam A. A randomised prospective comparison of the Flamingo Wallstent and Ultraflex stent for palliation of dysphagia associated with lower third oesophageal carcinoma. Gut. 2003;52(7):922-6.

8. Frimberger E. Endoscopic treatment of benign esophageal stricture. Endoscopy. 1983;15 Suppl 1:199-202.

9. Song HY, Park SI, Do YS, Yoon HK, Sung KB, Sohn KH, et al. Expandable metallic stent placement in patients with benign esophageal strictures: results of long-term follow-up. Radiology. 1997;203(1):131-6.

10. Zelenák K, Mistuna D, Lúcan J, Polácek H. Broken esophageal stent successfully treated by interventional radiology technique. Cardiovasc Intervent Radiol. 2010;33(3):643-5. doi:10.1007/s00270-009-9648-x. Epub 2009 Jul 14.

11. Guo JH, Teng GJ, Zhu GY, He SC, Fang W, Deng G, et al. Self-expandable esophageal stent loaded with $125 \mathrm{l}$ seeds: initial experience in patients with advanced esophageal cancer. Radiology. 2008;247(2):574-81. doi:10.1148/ radiol.2472070999. Epub 2008 Mar 18.

12. Zhongmin W, Xunbo H, Jun C, Gang H, Kemin C, Yu L, et al. Intraluminal radioactive stent compared with covered stent alone for the treatment of malignant esophageal stricture. Cardiovasc Intervent Radiol. 2012;35(2):351-8. doi:10.1007/s00270-011-0146-6. Epub 2011 Mar 24.

13. Bartelsman JF, Bruno MJ, Jensema AJ, Haringsma J, Reeders JW, Tytgat GN. Palliation of patients with esophagogastric neoplasms by insertion of a covered expandable modified Gianturco-Z endoprosthesis: experiences in 153 patients. Gastrointest Endosc. 2000;51(2):134-8.

14. Baron TH. Expandable metal stents for the treatment of cancerous obstruction of the gastrointestinal tract. N Engl J Med. 2001:344(22):1681-7.

15. Jager J, Langendijk H, Pannebakker M, Rijken J, de Jong J. A single session of intraluminal brachytherapy in palliation of oesophageal cancer. Radiother Oncol. 1995;37(3):237-40.

16. Sur RK, Levin CV, Donde B, Sharma V, Miszczyk L, Nag S. Prospective randomized trial of HDR brachytherapy as a sole modality in palliation of advanced esophageal carcinoma - an International Atomic Energy Agency study. Int J Radiat Oncol Biol Phys. 2002;53(1):127-33.

17. Raijman I, Siddique I, Ajani J, Lynch P. Palliation of malignant dysphagia and fistulae with coated expandable metal stents: experience with 101 patients. Gastrointest Endosc. 1998;48(2):172-9.

18. Homs MY, Steyerberg EW, Eijkenboom WM, Tilanus HW, Stalpers $\sqcup$, Bartelsman JF, et al. Single-dose brachytherapy versus metal stent 
placement for the palliation of dysphagia from oesophageal cancer: multicentre randomised trial. Lancet. 2004;364(9444):1497-504.

19. Polinder S, Homs MY, Siersema PD, Steyerberg EW, Dutch SIREC Study Group. Cost study of metal stent placement vs single-dose brachytherapy in the palliative treatment of oesophageal cancer. Br J Cancer. 2004;90(11):2067-72.

20. Nishimura Y, Nagata K, Katano S, Hirota S, Nakamura K, Higuchi F, et al. Severe complications in advanced esophageal cancer treated with radiotherapy after intubation of esophageal stents: a questionnaire survey of the Japanese Society for Esophageal Diseases. Int J Radiat Oncol Biol Phys. 2003;56(5):1327-32.

21. Yakami M, Mitsumori M, Sai H, Nagata Y, Hiraoka M, Nishimura Y, Development of severe complications caused by stent placement followed by definitive radiation therapy for T4 esophageal cancer. Int J Clin Oncol. 2003;8(6):395-8.

22. Shin JH, Song HY, Kim JH, Kim SB, Lee GH, Park Sl, et al. Comparison of temporary and permanent stent placement with concurrent radiation therapy in patients with esophageal carcinoma. J Vasc Interv Radiol. 2005;16(1):67-74.

23. Sundelöf $M$, Ye W, Dickman PW, Lagergren J. Improved survival in both histologic types of oesophageal cancer in Sweden. Int J Cancer. 2002;99(5):751-4.

24. Dai Z, Zhou D, Hu J, Zhang L, Lin Y, Zhang J, et al. Clinical application of iodine-eluting stent in patients with advanced esophageal cancer. Oncol Lett. 2013:6(3):713-8. Epub 2013 Jul 15.

25. Ogilvie AL, Dronfield MW, Ferguson R, Atkinson M. Palliative intubation of oesophagogastric neoplasms at fibreoptic endoscopy. Gut. 1982;23(12):1060-7.

26. Orringer MB. Substernal gastric bypass of the excluded esophagus-results of an ill-advised operation. Surgery. 1984;96(3):467-70.

27. Mannell A, Becker PJ, Nissenbaum M. Bypass surgery for unresectable oesophageal cancer: early and late results in 124 cases. Br J Surg. 1988;75(3):283-6.

28. Gupta NM, Saxena R, Nagi B. Esophageal exclusion and gastric bypass for unresectable carcinoma of the thoracic esophagus. Indian J Gastroenterol. 1989:8(2):77-9.

29. McGrath JP, Browne M, Riordan C, Ravi N, Reynolds JV. Expandable metal stents in the palliation of malignant dysphagia and oesophageal-respiratory fistulae. Ir Med J. 2001;94(9):270-2.

30. Sarper A, Oz N, Cihangir C, Demircan A, Isin E. The efficacy of self-expanding metal stents for palliation of malignant esophageal strictures and fistulas. Eur J Cardiothorac Surg. 2003;23(5):794-8.

31. Grundy A. The Strecker Esophageal stent in the management of oesophageal strictures: technique of insertion and early clinical experience. Clin Radiol. 1994;49(6):421-4.

32. Wagner HJ, Stinner B, Schwerk WB, Hoppe M, Klose KJ. Nitinol prostheses for the treatment of inoperable malignant esophageal obstruction. J Vasc Interv Radiol. 1994;5(6):899-904

33. Raijman I, Walden D, Kortan P, Haber GB, Fuchs E, Siemens M, et al. Expandable esophageal stents: initial experience with a new nitinol stent. Gastrointest Endosc. 1994:40(5):614-21.

34. Aoki T, Osaka Y, Takagi Y, Okada R, Shinohara M, Tsuchida A, et al. Comparative study of self-expandable metallic stent and bypass surgery for inoperable esophageal cancer. Dis Esophagus. 2001;14(3-4):208-11.

35. Sgourakis G, Gockel I, Karaliotas C, Moehler M, Schimanski CC, Schmidberger H, et al. Survival after chemotherapy and/or radiotherapy versus self-expanding metal stent insertion in the setting of inoperable esophageal cancer: a casecontrol study. BMC Cancer. 2012;12:70. doi:10.1186/1471-2407-12-70.

\section{Submit your next manuscript to BioMed Central and we will help you at every step:}

- We accept pre-submission inquiries

- Our selector tool helps you to find the most relevant journal

- We provide round the clock customer support

- Convenient online submission

- Thorough peer review

- Inclusion in PubMed and all major indexing services

- Maximum visibility for your research

Submit your manuscript at www.biomedcentral.com/submit
Biomed Central 